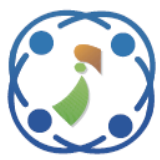

\title{
Probabilistic Voltage Profiles Analysis of Power System with Large Scale Wind Power Integration
}

\author{
Awan Uji Krismanto ${ }^{1}$ \\ Indra Soegiarto ${ }^{1}$ \\ Herlambang Setiadi ${ }^{2} *$ \\ Abraham Lomi $^{1} \quad$ Irrine Budi Sulistiawati $^{1}$ \\ Muhammad Abdillah ${ }^{3}$ \\ ${ }^{1}$ Electrical Engineering Department, Faculty of Industrial Technology, \\ Institut Teknologi Nasional, Malang, Indonesia \\ ${ }^{2}$ Faculty of Advanced Technology and Multidiscipline, Universitas Airlangga, Surabaya, Indonesia. \\ ${ }^{3}$ Department of Electrical Engineering, Universitas Pertamina, Jakarta, Indonesia \\ * Correspondence author’s E-mail: h.setiadi@ @stmm.unair.ac.id
}

\begin{abstract}
One of the main focus in integrating large scale wind power plant is how to maintain voltage stability under different power injection from wind farm. In this paper, effects of large-scale wind power plants on voltage profile of power system is investigated. Practical test system of South-West Sulawesi, Indonesia with integration of two large scale wind power plants are considered. It was monitored that the increasing wind enhanced the voltage profile of the system. Impacts of wind power integration on power system voltage profile were investigated in this paper. Probability analaysis based on MCS were conduted to observe the impacts of uncertain power injection from wind farm on voltage fluctuation. It was clearly monitored that the probability distribution of bus voltage varied accordingly depending to location and capacity of wind farm. It was also monitored that enhancement of voltage profiles increased in proportion with power injection from wind farm. Thus, having more power production from wind farm results in better loadability and eventually improved voltage stability condition of power system as shown in bus 31 (the voltage magnitude increased from 0.942 to $0.952 \mathrm{pu}$ ).
\end{abstract}

Keywords: MCS, Renewable energy, Uncertainty, Voltage profile, Wind power.

\section{Introduction}

The world power demand has been increasing significantly due to the escalation of industrialization and the increase of energy demand for consumer product. On the other hand, it is very difficult to accurately estimate the sustainability and availability of conventional fossil fuel [1]. Moreover, the massive increase of fossil fuel consumption introduces severe impacts on environment resulting global warming, climate change and excessive greenhouse effects. With the increase of electricity demand and several challenges and drawbacks of fossil fuel, energy security has become a major concern worldwide. Therefore, invention and exploration of novel energy resources in particular renewable energy resources has become a mandatory circumstance to ensure the energy securities.

In the past decade, renewable energy resources have become an important issue to provide sufficient energy supply for the load. Among various renewable energy resources, wind and solar are leading the growth of the installed renewable energy in power system network [2]. The worldwide installed capacity of wind power-based electricity generation has been increasing rapidly to around $700 \mathrm{GW}$ by the end of 2019. In Indonesia the $150 \mathrm{MW}$ wind power plant has been installed at South-West Sulawesi network and another $150 \mathrm{MW}$ is upcoming within few years. With the increasing installed capacity of renewable based power generation, it is necessary to have a comprehensive knowledge regarding possible impacts of renewable energy on power system operation. 
Modern power system, involving Indonesia power system network, incorporates more and more uncertain and uncontrollable energy resources to fulfil the electricity demand [3]. As mainly influenced by weather and environmental factors, uncertain power injection from renewable based power generation potentially alter power flow, effects transmission lines congestion and influences voltage profiles of the power system. The beneficial effects of integrating such energy resources in environmental and economic point of view are presented in $[4,5]$. It was reported that bringing renewable energy results in reduction in environmental and fuel costs. Moreover, it also has benefits to both climate and public health due to reducing $\mathrm{CO}_{2}$ emission and other pollutant. From power system operation point of view, it was monitored that additional power injection from renewable energy based power generation contributed to increase the voltage profiles of the system [6]. The enhancement of voltage profiles leads to the improvement of power system loadability.

Despite the advantages of installing renewable energy in power system network, the uncertainty and intermittency features of the renewable energy-based power generation result in more complex operation and control of the power system. To ensure energy conservation, time varying power demand should be continuously matched with the power generation [1]. Instantaneous change of power injection from renewable energy potentially introduce distortion of power balance in steady state operation of power system, which lead to oscillatory circumstance. Therefore, a fast compensation should be provided to maintain equilibrium point and stable operation of power system [7, 8]. Moreover, it potentially influenced resonance and interaction phenomenon in power system [9-11]. In case of higher share of renewable energy resources, power system reinforcement actions are required for overcoming network problem raised by these volatile sources [12]. Moreover, installed renewable energy based power generation may cause frequency and voltage variations, power factor reduction dan harmonic distortion [13].

From voltage stability point of view, one of the main concerns of integrating wind power plant is power injection from wind power plant which randomly affect the voltage stability of power system.[14]. Instantaneous and unpredictable change of injected power from wind power plant might affect dynamic/ transient voltage stability. The voltage stability concerns are also influenced by location of wind power plant. As most of the wind power plant are located in coastal of off-shore area, it requires a long transmission line to make a grid connection. The existence of long transmission line potentially affects the voltage profiles in particular under heavy loading condition and fluctuating power generation [15]. Moreover, implementation of asynchronous machines in variable speed wind power technologies absorbs a certain amount of reactive power. Hence, it also affects the reactive power flow and eventually voltage stability. A robust control algorithm is necessary to ensure voltage stability of the power system with high penetration of wind power plant. Hence, the voltage stability can be maintained under random power injection from wind power plant [16].

With either advantages or drawbacks impacts of integrating renewable energy, it is necessary to be able to capture the system behaviours under various power injection from those renewable based power plant. Generally, deterministic load flow is sufficient to capture system performance when uncertainties in power generation and load are not considered. The deterministic load flow only presenting the system behaviour according to the provided system operational data. It has a limitation in presenting the randomness in the power system. Therefore, with the increase level of uncertainties due to renewable power plant integration, more efficient tools are required to be able to capture the variability of system performance [10].

Many studies have been conducted to investigates the impacts of wind power penetration using probability approaches. Large scale wind power potentially affects the oscillatory condition of power system, therefore probabilistic analysis of small signal stability of power system with wind power has been analysis in [17-20]. It was monitored that uncertain power injections from wind power plant results in random trajectories movement of critical modes. Consequently, it potentially leads to unstable conditions when small perturbations were experienced by power system. A statistical analysis improved the ability to assess the power system performance and risk of instability under random wind power injection.

It was clearly reported from previous studies that uncertain power injection from wind power plant randomly influenced system dynamic behaviour involving the system voltage profiles. Even though, voltage instability might be better captured using a stochastic approach, lack of research has been conducted to investigated these concerns. In [21], a probabilistic density function of voltage instability has been presented, however, it did not provide a clear description regarding voltage stability performance of power system. Effects of random 
wind power injection on voltage stability of radial distribution network is presented in [22-24]. Probabilistic analysis of voltage profiles under different wind power injection in a simple transmission network is presented in [25]. Time series load flow analysis with integration of wind power is presented in [26]. The wind power was modelled using deterministic approach with limited time span. Therefore, it did not reflect the realistic scenarios of wind power.

This paper presents a probabilistic approach of voltage stability of power system with large-scale wind power integration. Realistic meteorological wind data are considered and applied to a practical test system to present more comprehensive voltage stability assessment. Monte Carlo (MC) analytical approach is implemented to provide precise estimation of wind power distribution function and realistic scenarios of power injections from wind power plant. The remainder of the paper is organised as follows. Probabilistic model of wind speed is presented in Section II. The MCS is described in Section III. Dynamic model of wind power plant is presented in Section IV. The comprehensive analysis, results discussions of voltage profile fluctuation is given in Section IV. Eventually, conclusions and contributions of this paper are highlighted in Section V.

\section{Dynamic models of wind power plant}

of fixed speed wind turbines in term of a limited variation in turbine rotor speed and reactive power compensation encouraged the development of variable speed wind turbine technology. Capability to operate in a wide range of wind speed variations is an important feature which should be considered in integrating wind power plant. Therefore, among wind power technology, doubly fed induction generator (DFIG) and fully rated wind energy conversion system have been used popularly worldwide.

In this research, a fully rated wind power generation is considered. Those direct driven wind power plant technology provides a full service and flexible operations of back-to-back inverter system for controlling and maintaining a stable to generated power under fast change of wind speed. The implementation of high pole count machines in full converter turbine allows gearbox-less configuration from drive-train, thus improving reliability [27]. The investigated wind power technology also offers independent real and reactive power control which improves variable operation capability. Moreover, direct connection of back-to-back inverter provides full decouple between mechanical and electrical sides of wind power plant. Hence, the fluctuation and frequency variation in

mechanical side would be fully isolated and not affect the frequency of the grid side.

A block diagram of dynamic model of fully rated wind generation is depicted in Fig. 1. The dynamic model fully rated wind power generator is comprising of dynamic model of induction generator and a detailed model of back to back inverter system as

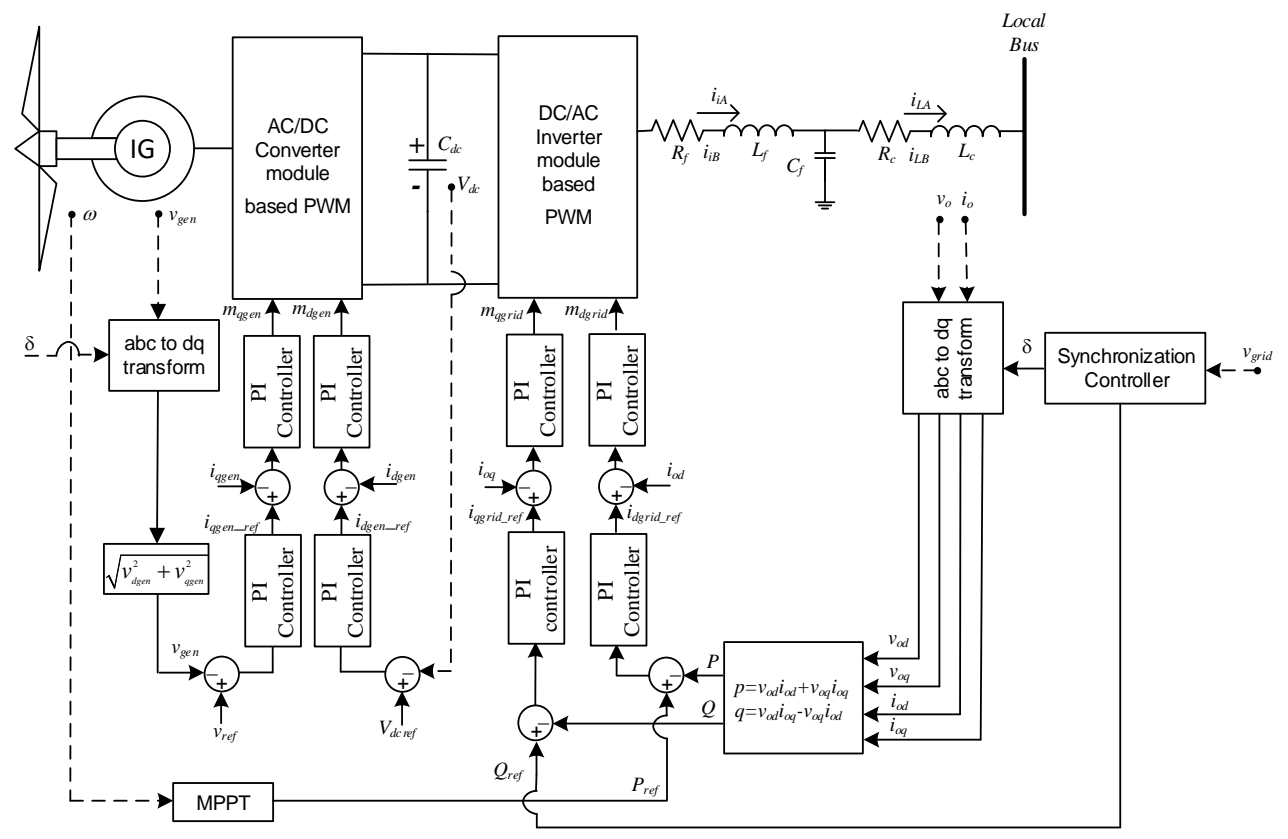

Figure. 1 Dynamic model of wind power generation 


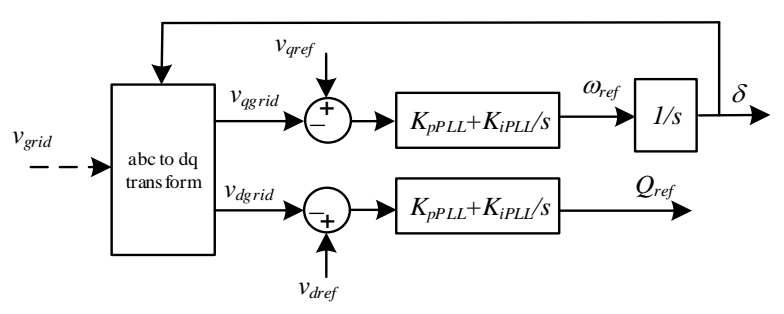

Figure. 2 PLL controller

presented in [11, 28]. In this research, it is assumed that the wind power plant is operated at a constant pitch angle. Hence, only controllers of back-to-back inverter system is considered. Control system of fully rated wind power generation is comprising of generator and grid side controllers. Which is responsible for facilitating variable speed operation capability under fluctuating condition of wind speed and controlling power flow to the grid while enhancing power quality respectively [29].

Maintaining a synchronous operation of wind power plant during grid tied mode of operation is very important to ensure stability of power system. The synchronisation mechanism is controlled using phase lock loop (PLL) controller as depicted in Fig. 2. The synchronisation controller determines reference angle, frequency and voltage values.

Dynamic behaviour of the PLL controller is represented by a set of auxiliary state variables $\left(\varphi_{d P L L}, \varphi_{q P L L}\right)$ as given by the following equation

$$
\frac{d \varphi_{d P L L}}{d t}=v_{d r e f}-v_{q g r i d}, \frac{d \varphi_{q P L L}}{d t}=v_{\text {qref }}-v_{d g r i d}
$$

The obtained error of reference and measured bus voltage is then regulated using PI controller to determine reference values of reactive power and angular frequency. The obtained reference values from synchronization controller are then applied to the local controller of grid-side converter control algorithms. Calculation of reference reactive power and angular frequency from PLL controller are given by the following equations

$$
\begin{aligned}
& Q_{\text {ref }}=K_{i P L L} \varphi_{d P L L}+K_{p P L L}\left(v_{d r e f}-v_{\text {dgrid }}\right) \\
& \omega_{\text {ref }}=K_{i P L L} \varphi_{d P L L}+K_{p P L L}\left(v_{\text {qref }}-v_{\text {qrid }}\right)
\end{aligned}
$$

The generator-side converter control is responsible for maintaining a stable condition of terminal generator and DC link voltage, allowing variable speed operation of the induction generator. Measured terminal generator and DC link voltage are compared to their reference values. The determined errors are then controlled using conventional PI control method to derive reference values of direct and quadrature currents. By considering $\beta_{d g e n}$ and $\beta_{\text {qgen }}$ as auxiliary state variables of outer control loop of generator side converter, state equations of the controller can be stated as

$\frac{d \beta_{d g e n}}{d t}=v_{d r e f}-v_{d c}, \frac{d \beta_{q g e n}}{d t}=v_{g e n \_r e f}-v_{g e n}$

The reference currents of generator side converter are given by

$$
\begin{aligned}
& i_{\text {dgen_ref }}=K_{i 21} \beta_{d g e n}+K_{p 21} v_{d r e f}-K_{p 21} v_{d c}(5) \\
& i_{\text {qgen_ref }}=K_{i 11} \beta_{\text {qgen }}+K_{p 11} v_{g e n \_r e f}-K_{p 11} v_{g e n}
\end{aligned}
$$

Output variables from the outer control loop are then applied to inner current control loop as reference values and compared to the actual values of generator currents $\left(i_{\text {dgen }}, i_{\text {qgen }}\right)$.

A similar algorithm is implemented to the current control loop to determine the modulation indices $\left(m_{d g e n}^{*}, m_{q g e n}^{*}\right)$ for the generator-side converter. These modulation indices are afterward employed as control variables of PWM switching scheme for the converter. Auxiliary state variables of $\gamma_{d g e n}$ and $\gamma_{q g e n}$ are required to provide state equation of the current controller as given by

$$
\frac{d \gamma_{d g e n}}{d t}=i_{d g e n \_r e f}-i_{d g e n}, \frac{d \gamma_{q g e n}}{d t}=i_{\text {qgen_ref }}-
$$

The algebraic equations of modulation indices reference signal for generator side converter are given by

$$
m_{d g e n}^{*}=K_{i 41} \gamma_{d g e n}+K_{p 41} v_{d g e n \_r e f}-K_{p 41} i_{d g e n}
$$

$$
m_{q g e n}^{*}=K_{i 31} \gamma_{q g e n}+K_{p 31} v_{q g e n \_r e f}-K_{p 31} i_{q g e n}
$$

Similar to the generator-side control, the grid-side inverter control in fully rated converter-based wind power plant is consisting of slow response outer and fast response inner control loops. In the outer control loop, the calculated active and reactive power reference values are compared to the measured active and reactive output power. The obtained error is then regulated by PI controller, yielding the reference 
values for the inner current control loop. By considering $\beta_{\text {dgrid }}$ and $\beta_{\text {qgrid }}$ as auxiliary state variables of the outer control loop of grid-side converter, state equations of the controller can be stated in the following equations

$\frac{d \beta_{d g r i d}}{d t}=P_{\text {ref }}-P, \frac{d \beta_{q g r i d}}{d t}=Q_{\text {ref }}-Q$

The reference currents of grid-side converter are calculated as follows

$$
\begin{aligned}
& i_{\text {dgrid_ref }}=K_{i 22} \beta_{\text {dgrid }}+K_{p 22} P_{\text {ref }}-K_{p 22} P \\
& i_{\text {qgrid_ref }}=K_{i 12} \beta_{\text {qgrid }}+K_{p 12} Q_{\text {ref }}-K_{p 12} Q
\end{aligned}
$$

\section{Method}

\subsection{Probabilistic model of wind speed}

The wind speed condition in a particular region is highly affected by many environmental factors such as irradiation of solar, the surface and complexity of terrain and humidity. In order to optimize the wind resource, it is necessary to accurately estimate the wind energy potential even though it is very difficult to predict and model the distribution of wind speed due to its stochastic nature. So far, a statistical method is the best approach to describe the wind speed nature. Among the probability density function, Weibull function is considered more versatile and widely implemented to capture the wind speed profiles. The Weibull probabilistic $f(v)$ and cumulative $F(v)$ distribution functions for a given wind speed can be presented as follows [27].

$$
\begin{aligned}
& f(v)=\frac{k}{c}\left(\frac{v_{w}}{c}\right)^{k-1} \exp \left[-\left(\frac{v_{w}}{c}\right)^{k}\right] \\
& F(v)=1-\exp \left[-\left(\frac{v_{w}}{c}\right)^{k}\right]
\end{aligned}
$$

Where $k$ and $c$ are related to shape and scale parameters of the Weibull distribution. The "shape parameter" represents average value of wind speed. The "shape parameter" describes the wind speed distribution. Higher " $k$ " and " $c$ " values indicates higher density of wind speed and how much the distribution of wind speed is stretched along the horizontal axis respectively.

Weibull parameters can be estimated through graphical and numerical methods. Comparing with the graphical methods, the numerical method that

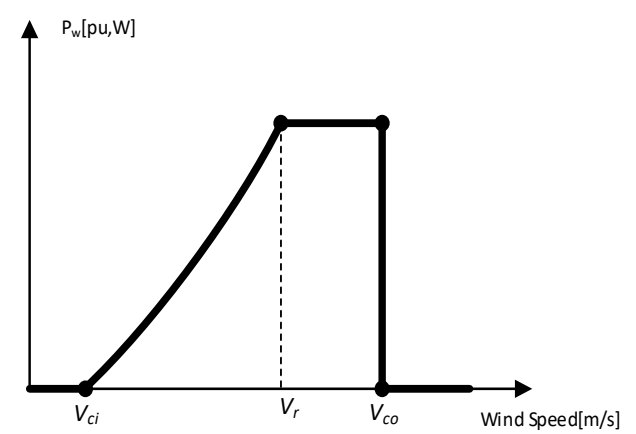

Figure. 3 Wind power curve

uses mathematical iterations provides more accurate results in determining the shape and scale parameters of Weibull pdf [30]. Among several estimation techniques, maximum likelihood method provides better accuracy in determining the Weibull parameters [30-32]. The $k$ and $c$ parameters can be obtained by iteratively solving the Eqs. (3) and (4) respectively.

$$
\begin{aligned}
& k=\left[\frac{\sum_{i=1}^{n} v_{i}^{k} \ln \left(v_{i}\right)}{\sum_{i=1}^{n} v_{i}^{k}}-\frac{\sum_{i=1}^{n} \ln \left(v_{i}\right)}{n}\right]^{-1} \\
& c=\left(\frac{1}{n} \sum_{i=1}^{n} v_{i}^{k}\right)^{\frac{1}{k}}
\end{aligned}
$$

Where $n$ represents the number of observations performed.

The obtained probability density function of wind speed is then implemented to estimate the distribution of generated power from wind power plant. The output power from wind power plant is influenced by mechanical characteristic of wind turbine, power output curve and actual wind speed values. Typical power curve of a particular wind turbine is depicted in Fig. 1. Wind turbine normally operates between cut-in $\left(V_{c i}\right)$ and cut-off speed $\left(V_{c o}\right)$. When operated between those limits, the generated power increases in proportion with the increase of wind speed. The nominal power output is reached when the wind speed is equal to rated speed $\left(V_{r}\right)$. However, under cut-in speed and above cut-off speed, the wind turbine should not be operated due to efficiency and safety reasons respectively [33].

Using the presented wind power curve, the generated power from wind power plant can be formulated as given by the following equation [34, $35]$.

$$
P_{w}\left(v_{w}\right)\left\{\begin{array}{c}
0 \text { for } v<v_{c i} \text { or } v>v_{c o} \\
\frac{v_{w}-v_{c i}}{v_{r}-v_{c i}} P_{w r} \text { for } v_{c i} \leq v \leq v_{r} \\
P_{w r} \text { for } v_{r}<v<v_{c o}
\end{array}\right.
$$


Where $P_{w}$ and $P_{w r}$ represent a power output at a particular wind speed and the equivalent rated power output of wind power plant. In this research, power injection from wind power plant is increasing proportionally to investigate impacts of increasing wind power penetration on power system voltage stability.

\subsection{Monte carlo simulation for probabilistic load flow analysis}

Integration of renewable based power generation creates novel challenges on planning and operation of power system. From load-flow point of view, random power injection from renewable power plant involving wind power causes power production to be neither continuous nor slightly controllable. Consequently, a novel approach in investigating power system performance under uncertainties is required.

With the increase of uncertainties in power system involving random power generation and load fluctuation, the deterministic power flow is not sufficient to capture entire power system performance. An acceptable solution to overcome the limitation of deterministic analysis is the use of stochastic models to represent the load flow condition considering uncertainties [3].

In general, the aim of power flow analysis is to solve a set of non-linear equations in order to find a power balance condition from determined initial conditions. A set of non-linear equations in power flow is representing as a set of differential-algebraic equations. The formulation of the power flow problems can be stated as.

$g(x)=0$

$\left[g^{P}(x) g^{Q}(x)\right]^{T}=0$

Where $g$ defines a set of algebraic equations correlated to power balance at network buses and $x$ the state vector.

The input or known quantities are the injected active power $(P)$ at all busbar ( $P$ and $Q$ or $P$ and $V$ are known) except the slack bus, the injected reactive power $(Q)$ at all the load busbar ( $P$ and $Q$ are known) and the voltage magnitude at all generator busbar $(P$ and $V$ are known). The algebraic equations for active and reactive power are given as follows.

$P_{i}=g_{i}^{P}\left(\delta_{1}, \delta_{2}, \ldots, \delta_{n}, V_{1}, V_{2}, \ldots, V_{n}\right)$

$Q_{i}=g_{i}^{Q}\left(\delta_{1}, \delta_{2}, \ldots, \delta_{n}, V_{1}, V_{2}, \ldots, V_{n}\right)$ where $i=1,2, \ldots, \mathrm{n} . \mathrm{n}$ represents the number of power buses, nonlinear voltage $(V)$ and phase $(\delta)$ relationships. More detail explanation of power flow procedures is represented in [36].

In probabilistic approach, the variables should be represented as random variables to obtain probability distribution function of state vector such as voltage profiles, losses and line flows. The active and reactive power from generation and load sides are considered by their probability distribution function. Since the aim of this research is to investigate the effects of wind power uncertainties, the wind power is modelled by using Weibull distribution function considering annual wind data with a minute resolution.

The probabilistic power flow analysis with random power production from wind power plant is conducted through Monte Carlo Simulation (MCS). The MCS is an iterative analytical method which evaluates performance of a set of deterministic models using sets of random variables as input. The process of MCS simulation in solving probabilistic power flow analysis considering random power injection from wind power is depicted in Fig.4. The main procedure of implementing $\mathrm{MC}$ method to investigate voltage profiles variations under random power injection from wind power plant is given as follows

- Estimate a probability distribution function (PDF) based on annual historical data of wind speed.

- Generate random wind speed values according to the estimated PDF. Subsequently, the wind power productions are calculated based-on those random numbers for power flow analysis purpose.

- Set a number of MC iteration based on the determined sample size of input and output variables.

- Iteratively, carry out power flow analysis and store the voltage profile results.

- From a set of obtained voltage profiles, the stochastic analytical technique is then conducted to investigate the fluctuation and distribution of voltage profiles under uncertain wind power injection.

- Eventually, the voltage profile conditions were assessed statistically to determine the risk of instability and voltage stability performance.

\section{Results and discussions}

Effect of uncertain power injection from wind 


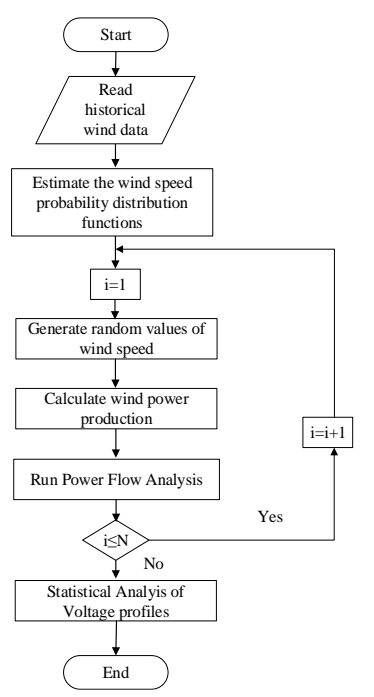

Figure. 4 Monte carlo simulation (MCS) for probabilistic voltage stability analysis

power plant on voltage profiles of a practical power system network was investigated in this paper. The South West Sulawesi $150 \mathrm{kV}$ interconnected power system is considered. This test system is realistic and real power system in developed country Indonesia. This test system is still under development as Indonesian government want to invest more renewable energy especially wind power system in this interconnected system. Hence this power plant can attract not only researcher but also practitioner to study the impact of integration wind power plant existing power plant. The selected power system network incorporates two $150 \mathrm{MW}$ wind power plants in Sidrap (bus 28) and Jeneponto (bus 9) as depicted in Fig. 5 [37].

The uncertainties are modelled using
Table 1. Weibull PDF parameters of wind speed

\begin{tabular}{ccc}
\hline Parameters & Sidrap & Jeneponto \\
\hline Scale $(c)$ & 4.5936 & 6.3312 \\
Shape $(k)$ & 1.7013 & 1.5526 \\
\hline
\end{tabular}

Table 2. Statistical features of wind power production

\begin{tabular}{ccc}
\hline Parameters & Sidrap & Jeneponto \\
\hline Average & 52.61592 & 73.99937 \\
Std. Dev. & 33.84156 & 45.09077 \\
\hline
\end{tabular}

probabilistic model of actual wind speed data to determine the power production from wind power plant. Annual wind speed data with hourly sampling resolution from the two regions of Sidrap and Jeneponto were considered. The historical annual wind speed data were estimated using Weibull probability distribution function (PDF) to provide realistic scenarios of wind speed distribution. Table 1 shows shape $(k)$ and scale $(c)$ parameters of the Weibull function for wind speed of the selected regions which are determined using the maximum likelihood method.

The obtained wind speed PDF is used to generate random value of wind speed. Power injections from the wind power plant were varied in accordance with the generated random values of wind speed. The power production of wind power plant is varying as a function of cut-in speed $\left(V_{c i}\right)$, rated speed $\left(V_{r}\right)$ and cutoff speed $\left(V_{c o}\right)$. The generated output power of wind power plant is calculated using (5). In this paper, the values of $V_{c i}, V_{r}$ and $V_{c o}$ are of $3 \mathrm{~m} / \mathrm{s}, 12.5 \mathrm{~m} / \mathrm{s}$ and 25 $\mathrm{m} / \mathrm{s}$ respectively.

The probabilistic analysis was conducted by considering random power injection from wind

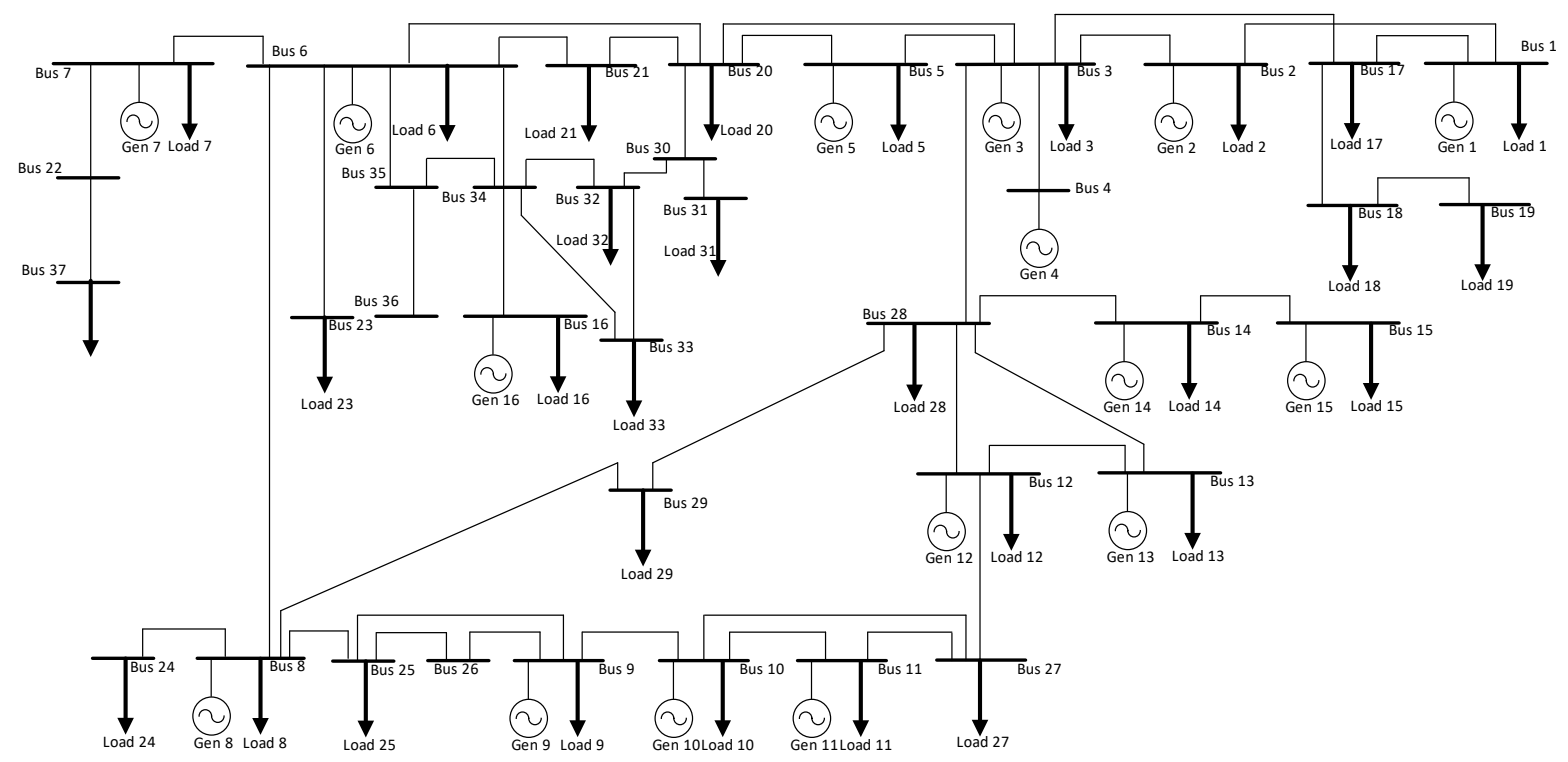

Figure. 5 South-west sulawesi $150 \mathrm{kV}$ network 

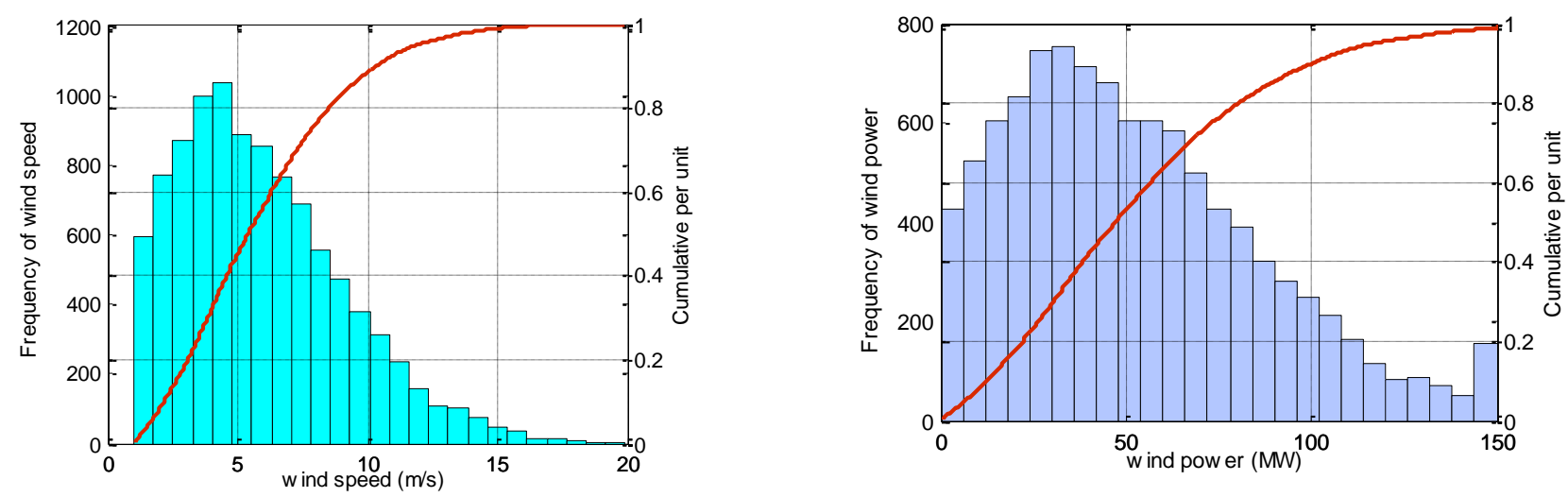

(a)
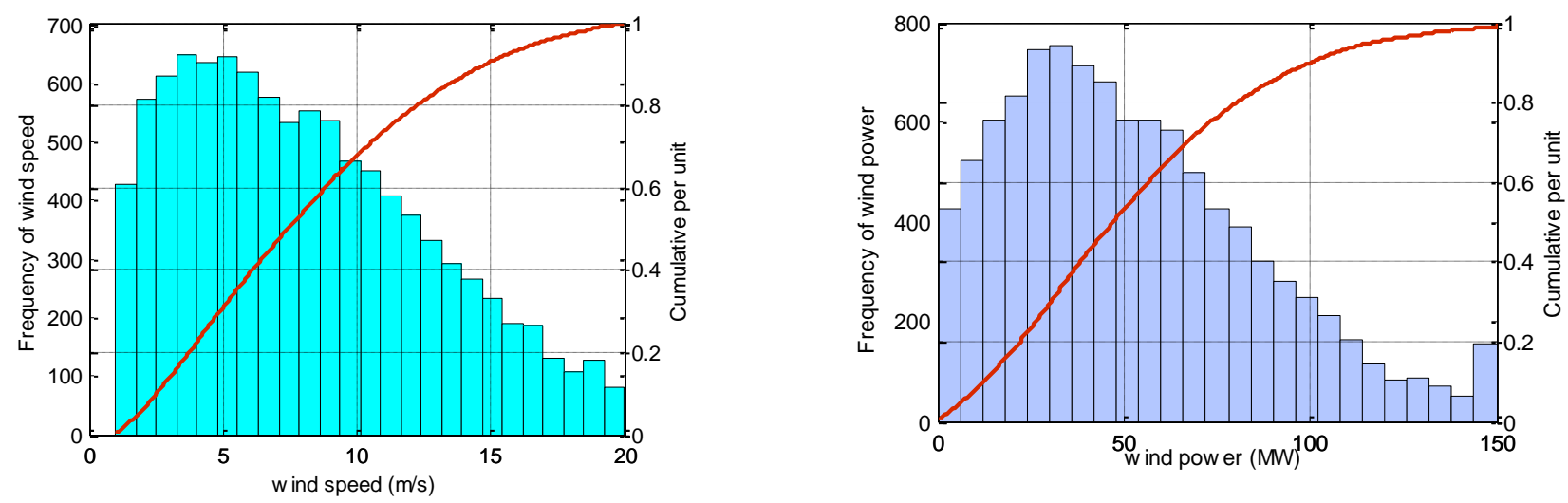

(b)

Figure. 6 Distribution of wind speed and wind power in: (a) Sidrap, (b) Jeneponto

power plant which have been created using the 10,000 samples of wind speed and wind power production. Fig.6 shows the wind speed distribution and variability of power production from wind power plant in Sidrap and Jeneponto in the form of histogram and cumulative distribution function (CDF). It was observed that in a particular area, the wind power production from a wind power plant is not linearly correlated with the wind speed due to the operation limits of wind turbine in the range of cutoff and cut-in speed. The statistical features of wind power production and wind speed are presented in Table 2. From the average and standard deviation values, it was suggested that the wind power production from Jeneponto area is higher than in Sidrap area as indicated by higher average value. Moreover, it was also monitored that higher standard deviation value in Jeneponto area indicates more fluctuating condition of wind power production than in Sidrap area.

Power flow direction in interconnected power system is mainly influenced by the location of generator unit, configuration of transmission lines and centre of load. Integration of novel generation unit would provide additional power injection which influence the power system operating condition involving power flow. Similarly, the power production from large scale wind power plant altered the direction of power flow, transmission line loading condition and hence influenced power losses. Depending where the generation unit are situated and how much powers are generated, integrating additional power plant may either enhance or deteriorate the voltage profile of the particular bus of the interconnected power system. Therefore, a comprehensive analysis should be carried out carefully to investigate voltage profiles fluctuation in various power injection scenarios from the operational generation units.

Variation of each bus voltage under maximum and minimum power injection from wind power plant is depicted in Fig. 7 It can be noticed that additional power injection from wind power plant introduces various effects on bus voltage. Enhancement of voltage profiles are observed in most of the bus voltage. A significant improvement is observed in bus 31 . Without wind power contribution, an undervoltage condition with 0.942 pu voltage magnitude was experienced in bus 31. With $300 \mathrm{MW}$ power 


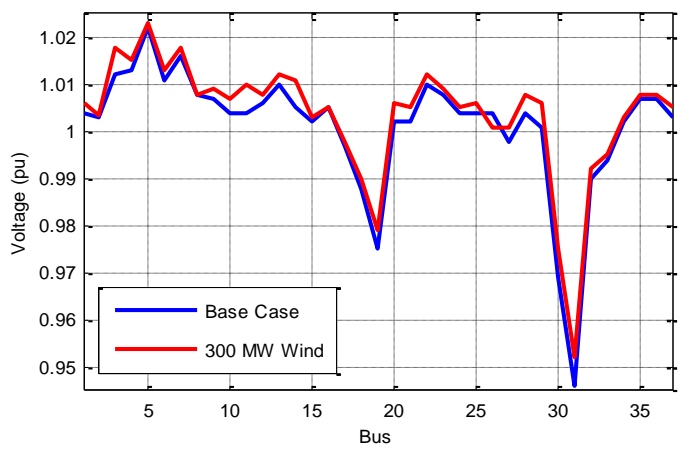

Figure. 7 Maximum and minimum bus voltage variations with wind power integration.

injection from wind power plant, voltage profile of the corresponding bus improved to $0.952 \mathrm{pu}$. Other bus voltages slightly vary either enhanced or deteriorated depending on the circumstances of the injected wind power production. It also can be observed that some buses have an effective voltage control hence the voltage magnitude of those buses was insensitive to generation variation.

A probabilistic analysis incorporates wind speed and wind power uncertainties is required to capture more realistic condition of power system operation. 10,000 data of wind power from Sidrap and Jeneponto areas are generated according to their wind speed probability distribution function. The generated wind power data are then randomly sampled through Monte Carlo Simulation (MCS) methods to realize the uncertain condition of wind power integration in interconnected power system.

According to Fig. 7, the risk of fluctuating conditions of bus voltage potentially occurred at bus 19, 30, 31, and 32. Therefore, the probabilistic analysis is focused on the investigation of voltage profiles of those marginal and critical buses. Three study cases are considered in this research to investigate the impacts of having random power injection from wind power plant. The first and second study cases considered effect of wind power integration in Sidrap (bus 28) and Jeneponto (bus 9) separately. While the third study case investigated the effect of integration of wind farm in Sidrap and Jeneponto simultaneously.

Figure 8 shows the histogram and cumulative distribution of voltage profiles at bus 19 and 30, 31 and 32 with random power injection from wind farm in Sidrap (bus 28). It was noticed that bus 19 was insensitive to variation of wind power. Most of the voltage profiles was around 0.976 under different power injection from the considered wind farm. Instead, at bus 30 and 32 , the range of voltage variations is considerably narrower from 0.973 to $0.976 \mathrm{pu}$ and from 0.9901 to 0.9907 pu respectively.
More significant voltage fluctuation was monitored at bus 31 as indicated by wider range of voltage fluctuations. The voltage profile of the considered bus varied from 0.9475 to $0.9495 \mathrm{pu}$. Even though the additional power from wind farm in Sidrap (bus 28) enhanced the voltage profile, the under-voltage condition was still monitored at bus 31 as indicated

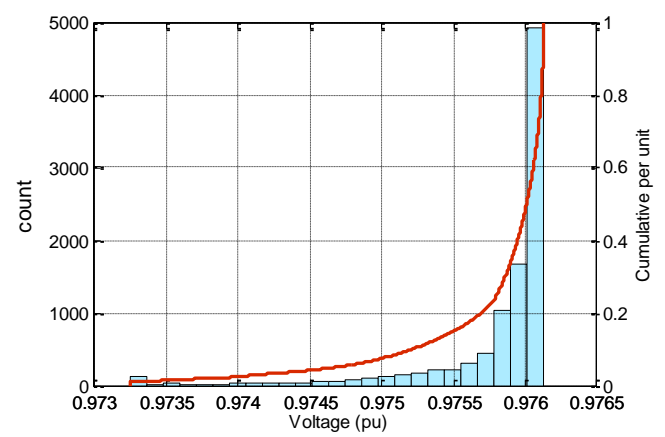

(a)

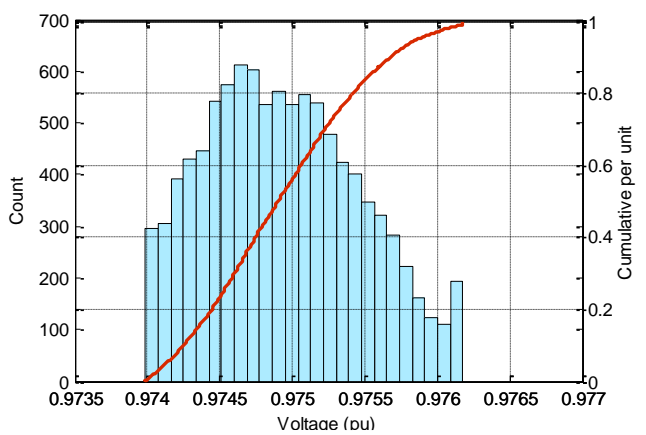

(b)

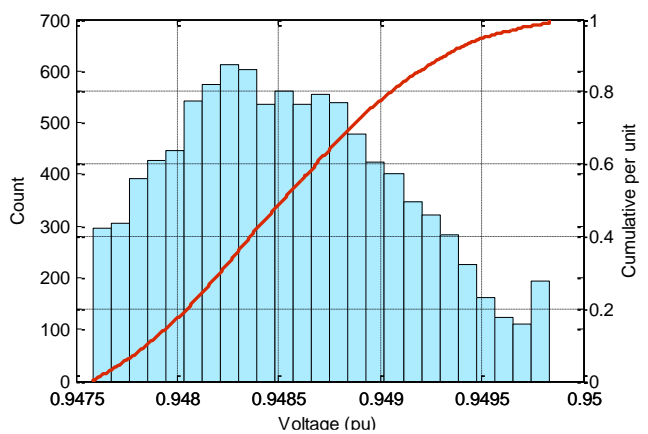

(c)

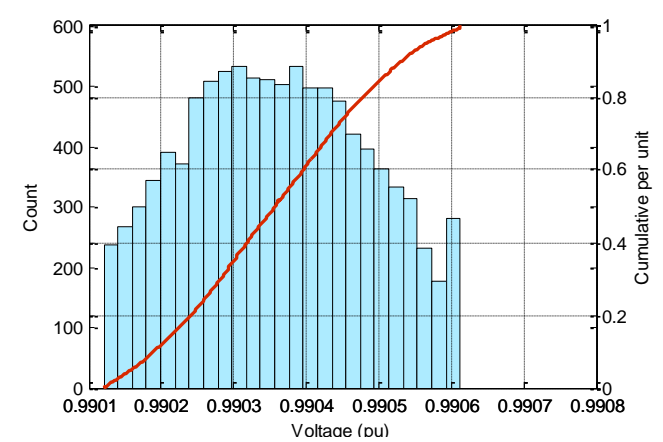

(d)

Figure. 8 Histogram and cumulative distribution of voltage with wind power in: Sidrap (bus 28): (a) Bus 19,

(b) Bus 30, (c) Bus 31, (d) Bus 40 
by the voltage profile of below $0.95 \mathrm{pu}$.

The second study case investigated fluctuation of voltage profiles with integration of wind farm in Jeneponto (bus 9). Fig. 9 shows the histogram and cumulative distribution of voltage profiles at bus 19 , 30, 31 and 32 with uncertain wind power in Jeneponto. It was noticed that bus 32 had an effective

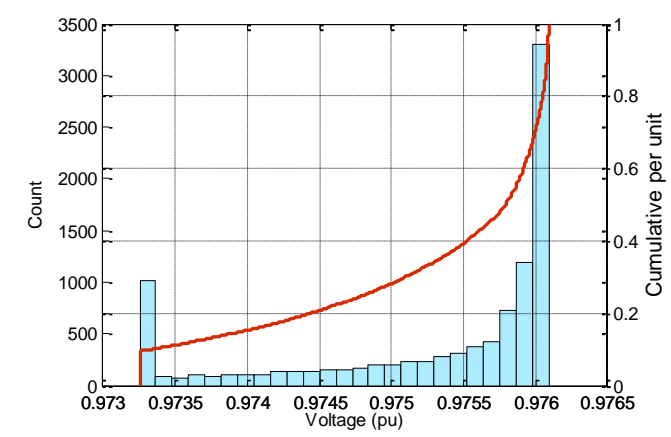

(a)

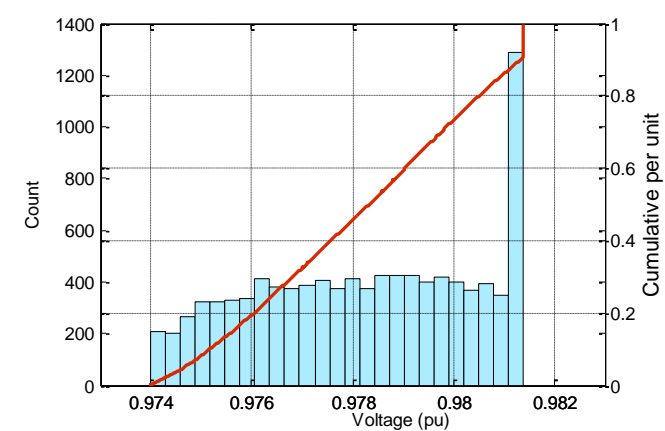

(b)

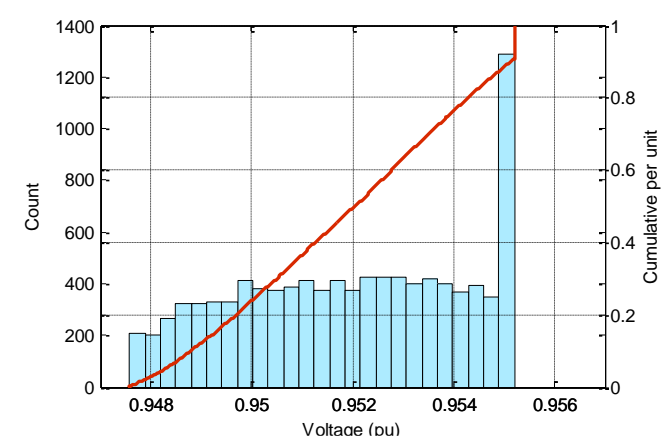

(c)

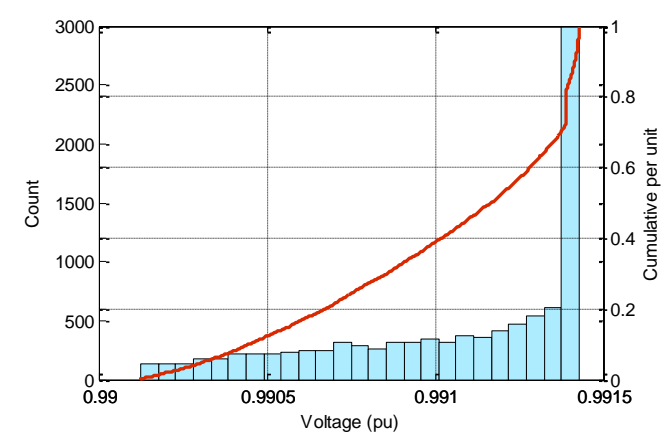

(d)

Figure. 9 Histogram and cumulative distribution of voltage with wind power in Jeneponto (bus 9): (a) Bus 19, (b) Bus 30, (c) Bus 31, (d) Bus 32 voltage control. The voltage of the bus 32 was relatively remaining constant around $0.9915 \mathrm{pu}$. A

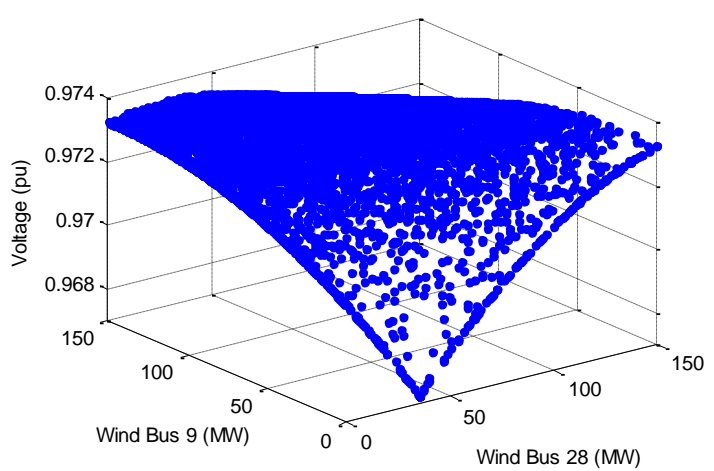

(a)

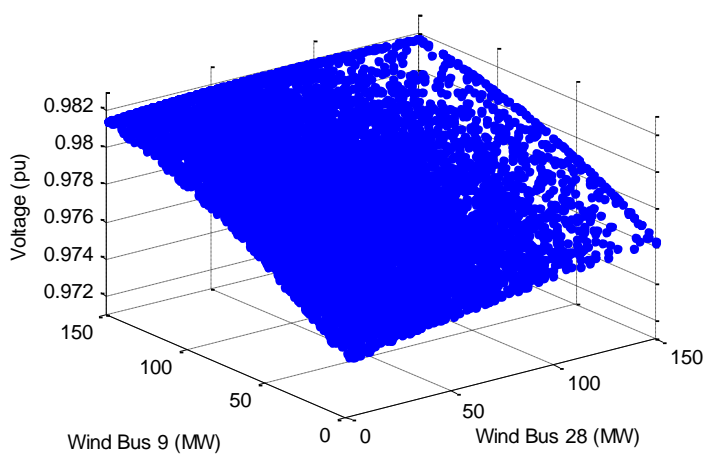

(b)

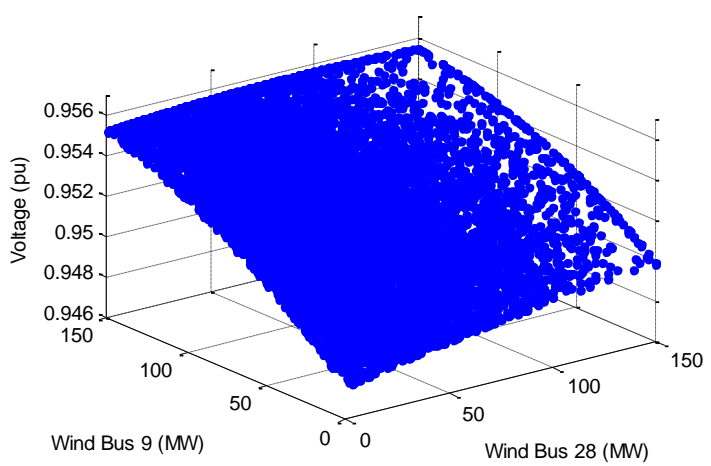

(c)

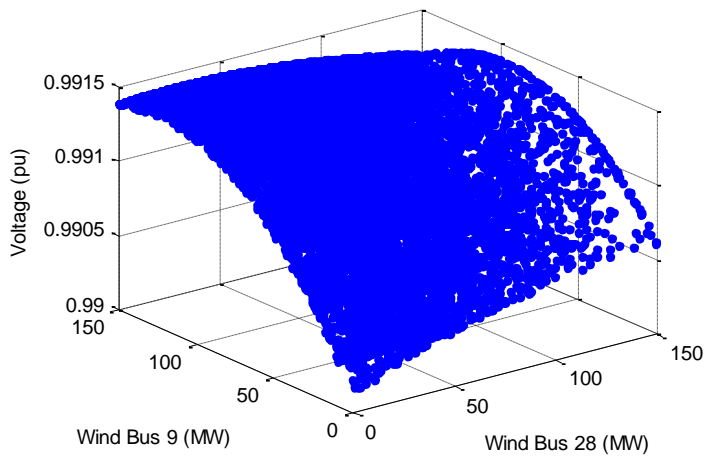

(d)

Figure. 10 Voltage profile variations of with wind power in Jeneponto (bus 9) and Sidrap (bus 28): (a) Bus 19, (b) Bus 30, (c) Bus 31, (d) Bus 32 
narrow range of voltage variations was observed at bus 19 and 30. The voltages profiles of bus 19 and 30 slightly varied from 0.973 to $0.976 \mathrm{pu}$ and from 0.974 to 0.981 pu respectively. Similar to previous study case, wider voltage fluctuation was monitored at bus 31. The voltage of bus 31 varied from 0.948 to 0.955 pu. The advantage effect of having wind farm in Jeneponto on system voltage stability was observed. The integration of wind farm in Jeneponto contributed to overcome the under-voltage condition at bus 31 .

In third study case, two wind farms in Sidrap and Jeneponto were integrated simultaneously, introduced more uncertain condition to the power system operation. Fig. 10 shows the fluctuation of bus $19,30,31$ and 32. It was noticed that under two sources of uncertainties of wind power from Sidrap and Jeneponto, voltage profiles of the investigated bus varied accordingly. More power injection from wind power plant in different locations altered the power flow and more importantly reduced the transmission line congestions in vast areas. It enhanced system load-ability and hence the voltage can survive under higher loading conditions of power system operations.

Fig. 11 shows the histogram and cumulative distribution of voltage profiles at bus 19 and 30, 31 and 32 with random power injection from wind farm in Jeneponto (bus 9) and Sidrap (bus 28). It was noticed that bus 19 was insensitive to variation of wind power. Most of the voltage profiles was around 0.976 under different power injection from the considered wind farms. Instead, at bus 30 and 32, the range of voltage variations is considerably narrower from 0.974 to $0.981 \mathrm{pu}$ and from 0.9905 to $0.9915 \mathrm{pu}$ respectively. More significant voltage fluctuation was monitored at bus 31 as indicated by wider range of voltage fluctuations. The voltage profile of the considered bus varied from 0.948 to $0.955 \mathrm{pu}$. The additional power from wind farm in Jeneponto (bus 9) and Sidrap (bus 28) enhanced the voltage profile. Only few under-voltage conditions were monitored at bus 31 . With additional power injection from those two wind farms, the voltage profile of bus 31 mostly above $0.95 \mathrm{pu}$, enhanced the static voltage stability condition of the corresponding bus.

From those three study cases, it was clearly monitored that the distribution of voltage profiles of the investigated bus did not followed a pure normal or gaussian distribution function. It was because the sources of uncertainties (wind power) had different probabilistic distribution function such as Weibull distribution function.

The detail statistical features of voltage profiles

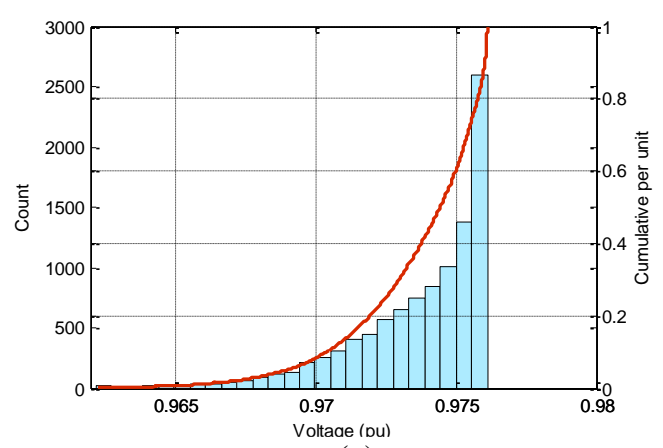

(a)

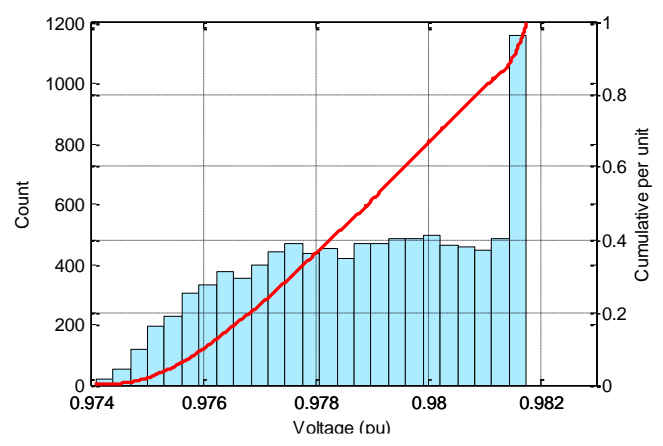

(b)

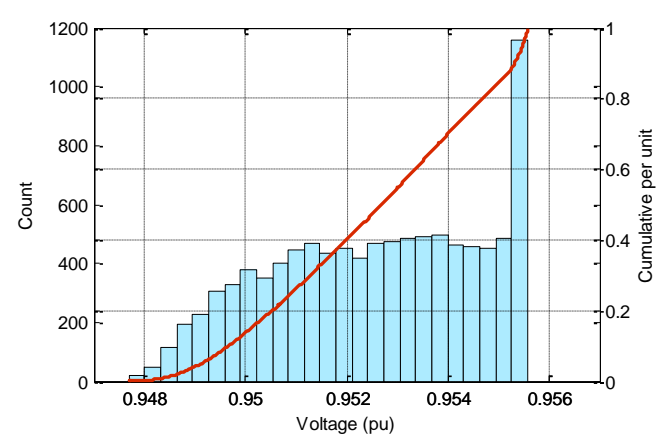

(c)

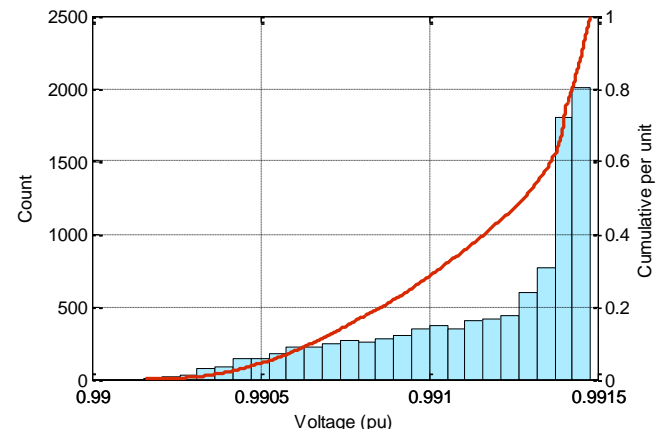

(d)

Figure 11 Histogram and cumulative distribution of voltage with wind power in Jeneponto (bus 9) and Sidrap (bus 28): (a) Bus 19, (b) Bus 30, (c) Bus 31, (d) Bus 32

of the investigated bus are presented in Table 3. It is noticed that effects of uncertain power injection from wind power plant varies depending on the location of wind farm. Under second case study, higher deviation values of voltage in bus 30,31 and 32 was monitored. 
Table 3. Statistical features of voltage profiles

\begin{tabular}{ccccccc}
\hline \multirow{2}{*}{ Bus } & \multicolumn{2}{c}{ Case I } & \multicolumn{2}{c}{ Case II } & \multicolumn{2}{c}{ Case III } \\
& Avg. & Std. & Avg. & Std. & Avg. & Std. \\
\hline \multirow{2}{*}{$\begin{array}{c}\text { 19 } \\
30\end{array}$} & 0.975 & 0.00052 & 0.975 & 0.00095 & 0.976 & 0.00238 \\
31 & 0.974 & 0.00052 & 0.978 & 0.00216 & 0.979 & 0.00198 \\
32 & 0.948 & 0.00054 & 0.951 & 0.00223 & 0.953 & 0.0021 \\
\hline
\end{tabular}

These indicated more fluctuating condition of voltage in bus 30, 31, and 32 when power injection from wind farm in Jeneponto was considered. Moreover, bus 19 had higher deviation value when two wind farms were integrated to the system. It indicated more fluctuating voltage condition of the corresponding bus. It also noticed that the voltage profile increased in proportion with the increase of power injection from wind farm.

\section{Conclusions}

Impacts of wind power integration on power system voltage profile were investigated in this paper. Probability analaysis based on MCS were conduted to observe the impacts of uncertain power injection from wind farm on voltage fluctuation. It was clearly monitored that the probability distribution of bus voltage varied accordingly depending to location and capacity of wind farm. It was also monitored in bus 31 enhancement of voltage profiles increased in proportion with power injection from wind farm (voltage profile increase from 0.942 to 0.952 ). Moreover, the increased voltage profiles not only emerges in bus 31 but also in other bus. Thus, having more power production from wind farm results in better load-ability and eventually improved voltage stability condition of power system. Further research can be conducted by investigated the impact of replacing one conventional power plant with wind based power plant in power system stability.

\section{Conflicts of interest}

"The authors declare no conflict of interest."

\section{Author contributions}

"Conceptualization, Awan Uji Krismanto, Irrine Budi Sulistiawati and Indra Soegiarto; methodology, Awan Uji Krismanto, Abraham Lomi and Herlambang Setiadi; Awan Uji Krismanto, Indra Soegiarto and Muhammad Abdillah; validation, Awan Uji Krismanto, Irrine Budi Sulistiawati and Indra Soegiarto; formal analysis, Awan Uji Krismanto, Abraham Lomi and Herlambang Setiadi; investigation, Awan Uji Krismanto and Muhammad Abdillah; resources, Awan Uji Krismanto; writing original draft preparation, Awan Uji Krismanto; writing review and editing, Irrine Budi Sulistiawati, Abraham Lomi and Indra Soegiarto; visualization, Awan Uji Krismanto, Muhammad Abdillah, and Herlambang Setiadi. All authors have read and agreed to the published version of the manuscript".

\section{References}

[1] D. I. Leon Freis, Renewable Energy in Power System. West Sussex, United Kingdom: John Wiley \& Sons, Ltd, 2008.

[2] Jean Daniel Pitteloud, "Global Wind Installations", 2020. .

[3] F. M. Gonzalez-Longatt, Advanced Smart Grid Functionalities Based on PowerFactory. Switzerland: Springer International Publishing, 2018.

[4] I. A. Nassar, K. Hossam, and M. M. Abdella, "Economic and environmental benefits of increasing the renewable energy sources in the power system", Energy Reports, Vol. 5, pp. 1082-1088, 2019, doi: https://doi.org/10.1016/j.egyr.2019.08.006.

[5] D. Topić, S. Vezmar, A. Spajić, D. Šljivac, and L. Jozsa, "Positive and Negative Impacts of Renewable Energy Sources", Int. J. Electr. Comput. Eng. Syst., Vol. 5, pp. 15-23, Jan. 2014.

[6] R. Bayindir, Ş. Demirbaş, E. Irmak, U. Cetinkaya, A. Ova, and M. Yeşil, Effects of renewable energy sources on the power system. 2016.

[7] A. U. Krismanto, M. Nadarajah, and O. Krause, "Influence of renewable energy based microgrid on low frequency oscillation of power systems", Asia Pacific Power Energy Engineering Conference. IEEE, Brisbane, QLD, 2015.

[8] Z. Conka, "Impact of Renewable Energy Sources on Power System Stability", Sci. J. Riga Tech. Univ., Vol. 32, pp. 29-34, Nov. 2014, doi: 10.7250/pee.2014.004.

[9] A. U. Krismanto, N. Mithulananthan, and O. 
Krause, "Microgrid Impact on Low Frequency Oscillation and Resonance in Power System", ISGT Asia Pacific 2016. Melbourne, 2016.

[10] A. U. Krismanto and N.Mithulanthan, "Probabilistic Small Signal Stability Analysis of Autonomous Wind-Diesel Microgrid", In: Proc. of ISGT Asia Pacific 2017, Auckland, New Zealand, 2017.

[11] A. U. Krismanto and M. Nadarajah, "Identification of Modal Interaction and Small Signal Stability in Autonomous Microgrid Operation", IET Gen. Transm. Distrib., 2017, doi: 10.1049/iet-gtd.2017.1219.

[12] G. Balaban, G. C. Lazaroiu, V. Dumbrava, and C. A. Sima, "Analysing Renewable Energy Source Impacts on Power System National Network Code", Inventions, Vol. 2, No. 3. 2017, doi: 10.3390/inventions2030023.

[13] M. Farhoodnea, A. Mohamed, H. Shareef, and H. Zayandehroodi, Power Quality Impact of Renewable Energy Based Generators and Electric Vehicles on Distribution Systems, Vol. 11. 2013.

[14] M. E. Shimy, M. A. L. Badr, and O. M. Rassem, Impact of large scale wind power on power system stability. 2008.

[15] Z. Bi and C. Gao, "Power System Dynamic Voltage Stability Analysis Considering Wind Power", In: Proc. of 2014 IEEE 12th International Conference on Dependable, Autonomic and Secure Computing, 2014, pp. 129-132, doi: 10.1109/DASC.2014.32.

[16] T. Huang, J. Ma, and W. Wang, "Study on transient voltage stability of wind farm incorporated system with reactive power compensation device", In: Proc. of 2014 International Conference on Power System Technology, pp. 2642-2646, 2014, doi: 10.1109/POWERCON.2014.6993619.

[17] C. Yan, L. Zhou, W. Yao, J. Wen, and S. Cheng, "Probabilistic small signal stability analysis of power system with wind power and photovoltaic power based on probability collocation method", Glob. Energy Interconnect., Vol. 2, No. 1, pp. 19-28, 2019, doi: https://doi.org/10.1016/j.gloei.2019.06.003.

[18] Z. Wang, C. Shen, and L. Feng, "Probabilistic Analysis of Small Signal Stability for Power Systems With High Penetration of Wind Generation", IEEE Trans. Sustain. Energy, Vol. 7, pp. 1-12, Mar. 2016, doi: 10.1109/TSTE.2016.2532359.

[19] S. Q. Bu, W. Du, H. F. Wang, Z. Chen, L. Y. Xiao, and H. F. Li, "Probabilistic Analysis of Small-Signal Stability of Large-Scale Power
Systems as Affected by Penetration of Wind Generation", IEEE Trans. Power Syst., Vol. 27, No. 2, pp. 762-770, 2012, doi: 10.1109/TPWRS.2011.2170183.

[20] Z. Wei et al., "Probabilistic small signal stability analysis of power system with large scale wind power", In: Proc. of 2014 IEEE Conference and Expo Transportation Electrification AsiaPacific (ITEC Asia-Pacific), pp. 1-4, 2014, doi: 10.1109/ITEC-AP.2014.6941214.

[21] Z. Ma, H. Chen, and Y. Chai, "Analysis of voltage stability uncertainty using stochastic response surface method related to wind farm correlation", Prot. Control Mod. Power Syst., Vol. 2, No. 1, p. 20, 2017, doi: 10.1186/s41601017-0051-3.

[22] W. Vicente, R. Caire, and N. Hadjsaid, "Probabilistic load flow for voltage assessment in radial systems with wind power", Int. J. Electr. Power Energy Syst., Vol. 41, pp. 27-33, Oct. 2012, doi: 10.1016/j.ijepes.2012.02.014.

[23] K. S. Narayan and A. Kumar, "Impact of wind correlation and load correlation on probabilistic load flow of radial distribution systems", In: Proc. of 2015 IEEE International Conference on Signal Processing, Informatics, Communication and Energy Systems (SPICES), , pp. 1-5, 2015, doi: 10.1109/SPICES.2015.7091506.

[24] G. E. C. Flores and M. Illindala, "Data-driven probabilistic power flow analysis for a distribution system with Renewable Energy sources using Monte Carlo Simulation", In: Proc. of 2017 IEEE/IAS 53rd Industrial and Commercial Power Systems Technical Conference (I\&CPS), pp. 1-8, 2017, doi: 10.1109/ICPS.2017.7945118.

[25] N. D. Hatziargyriou, T. S. Karakatsanis, and M. I. Lorentzou, "Voltage control settings to increase wind power based on probabilistic load flow", In: Proc. of 2004 International Conference on Probabilistic Methods Applied to Power Systems, 2004, pp. 737-741.

[26] B. Muruganantham and R. Gnanadass, "Wind Integrated Time series load flow analysis for a Practical Distribution System", Rev. Fac. Ing. Univ. Antioquia, pp. 33-39, 2017.

[27] S. Chakraborty, M. G. Simoes, and W. E. Kramer, Power Electronics for Renewable and Distributed Energy Systems, 1st ed. London, UK: Springer-Verlag London, 2013.

[28] A. U. Krismanto, N. Mithulananthan, and O. Krause, "Stability of Renewable Energy based Microgrid in Autonomous Operation", Sustain. Energy, Grids Networks, Vol. 13, pp. 134-147, 
2018 , https://doi.org/10.1016/j.segan.2017.12.009.

[29] N. D. Caliao, "Dynamic modelling and control of fully rated converter wind turbines", Renew. Energy, Vol. 36, No. 8, pp. 22872297, 2011.

[30] P. A. C. Rocha, R. C. D. Sousa, C. F. D. Andrade, and M. E. V. D. Silva, "Comparison of seven numerical methods for determining Weibull parameters for wind energy generation in the northeast region of Brazil", Appl. Energy, Vol. 89, pp. 395-400, 2012.

[31] J. V. Seguro and T. W. Lambert, "Modern estimation of the parameters of the Weibull wind speed distribution for wind energy analysis", Elsevier J. Wind Eng. Ind. Aerodyn., Vol. 85, pp. 75-84, 2000.

[32] W. Werapun, Y. Tirawanichakul, and J. Waewsak, "Comparative study of five methods to estimate Weibull parameters for wind speed on Phangan Island, Thailand," Energy Procedia, Vol. 79, pp. 976981, 2015.

[33] W. Zhou, C. Lou, Z. Li, L. Lu, and H. Yang, "Current status of research on optimum sizing of stand-alone hybrid solar-wind power generation systems", Appl. Energy, Vol. 87, pp. 380-389, 2010.

[34] J. Hetzer, D. C. Yu, and K. Bhattarai, "An Economic Dispatch Model Incorporating Wind Power", IEEE Trans. Energy Convers., Vol. 23, No. 2, pp. 603-611, 2008.

[35] G. L. a, H. Yuea, M. Zhoua, and J. Weib, "Probabilistic assessment of oscillatory stability margin of power systems incorporating wind farms", Electr. Power Energy Syst., Vol. 58, pp. 47-56, 2014.

[36] H. Saadat, Power System Analysis McGraw-Hill Series in Electrical Computer Engineering. .

[37] R. D. Muhammad, S. Herlambang, L. Dwi, and Y. Y. Muhammad, "Modal analysis and stability enhancement of $150 \mathrm{kV}$ Sulselrabar electrical system using PSS and RFB based on cuckoo search algorithm", Int. J. Electr. Eng. Informatics, Vol. 9, No. 4, pp. 800-812, 2017.

\begin{tabular}{|c|c|}
\hline$\varphi_{d P L L}$ & $\begin{array}{l}\text { Auxiliary state variable in D } \\
\text { axis }\end{array}$ \\
\hline$\varphi_{q P L L}$ & $\begin{array}{l}\text { Auxiliary state variable in Q } \\
\text { axis }\end{array}$ \\
\hline$\beta_{\text {dgen }}$ & $\begin{array}{l}\text { Auxiliary state variable of outer } \\
\text { control loop of generator side } \\
\text { converter in D axis }\end{array}$ \\
\hline$\beta_{\text {qgen }}$ & $\begin{array}{l}\text { Auxiliary state variable of outer } \\
\text { control loop of generator side } \\
\text { converter in Q axis }\end{array}$ \\
\hline$i_{\text {dgen }}$ & $\begin{array}{l}\text { Generator actual current in D } \\
\text { axis }\end{array}$ \\
\hline$i_{\text {qgen }}$ & $\begin{array}{l}\text { Generator actual current in } \mathrm{Q} \\
\text { axis }\end{array}$ \\
\hline$m_{d g e n}^{*}$ & $\begin{array}{l}\text { Modulation index } \\
\text { generator-side } \\
\text { axis }\end{array}$ \\
\hline$m_{q g e n}^{*}$ & $\begin{array}{l}\text { Modulation } \begin{array}{c}\text { index } \\
\text { generator-side } \\
\text { axis }\end{array} \\
\text { conveter in } \mathrm{Q}\end{array}$ \\
\hline$\beta_{\text {dgrid }}$ & $\begin{array}{l}\text { Auxiliary state variable of outer } \\
\text { control loop of grid side } \\
\text { converter in D axis }\end{array}$ \\
\hline$\beta_{\text {qgrid }}$ & $\begin{array}{l}\text { Auxiliary state variable of outer } \\
\text { control loop of grid side } \\
\text { converter in Q axis }\end{array}$ \\
\hline$i_{\text {dgrid_ref }}$ & $\begin{array}{l}\text { Grid side current reference in D } \\
\text { axis }\end{array}$ \\
\hline$i_{\text {qgrid_ref }}$ & $\begin{array}{l}\text { Grid side current reference in Q } \\
\text { axis }\end{array}$ \\
\hline$f(v)$ & $\begin{array}{l}\text { Weibull probabilistic } \\
\text { distribution function }\end{array}$ \\
\hline$F(v)$ & $\begin{array}{l}\text { Weibull cumulative distribution } \\
\text { function }\end{array}$ \\
\hline$k$ & $\begin{array}{l}\text { Shape parameters of the } \\
\text { Weibull distribution }\end{array}$ \\
\hline$c$ & $\begin{array}{l}\text { Scale parameters of the Weibull } \\
\text { distribution }\end{array}$ \\
\hline$P$ & Active power \\
\hline$Q$ & Reactive power \\
\hline$V$ & Nonlinear voltage \\
\hline$\delta$ & Phase relationships \\
\hline$g$ & Algebraic equations \\
\hline$x$ & State vector \\
\hline
\end{tabular}

\section{Appendix}

Table 4. List of notations used in this paper

\begin{tabular}{|l|l|}
\hline Symbol & \multicolumn{1}{c|}{ Meaning } \\
\hline$V_{c i}$ & Cut in wind turbine speed \\
\hline$V_{c o}$ & Cut off wind turbine speed \\
\hline$V_{r}$ & Rated speed \\
\hline$P_{w}$ & $\begin{array}{l}\text { Power output at a particular } \\
\text { wind speed }\end{array}$ \\
\hline$P_{w r}$ & $\begin{array}{l}\text { Equivalent rated power output } \\
\text { of wind power plant }\end{array}$ \\
\hline
\end{tabular}

